\title{
Retinoblastoma cM0 TNM Finding v7
}

National Cancer Institute

\section{Source}

National Cancer Institute. Retinoblastoma CMO TNM Finding v7. NCI Thesaurus. Code C88776.

Retinoblastoma with no metastasis. (from AJCC 7th Ed.) 